\title{
17-AAG-Induced Activation of the Autophagic Pathway in Leishmania Is Associated with Parasite Death
}

\author{
Antonio Luis de O. A. Petersen ${ }^{1}$, Benjamin Cull ${ }^{2} \mathbb{D}$, Beatriz R. S. Dias ${ }^{1} \mathbb{D}$, Luana C. Palma ${ }^{1,3}$, Yasmin da S. Luz ${ }^{1}$, \\ Juliana P. B. de Menezes ${ }^{1}\left(\mathbb{D}\right.$, Jeremy C. Mottram ${ }^{2,4}$ (D) and Patrícia S. T. Veras $1,5, *(\mathbb{D}$
}

1 Laboratory of Parasite-Host Interaction and Epidemiology (LAIPHE), Gonçalo Moniz Institute-FIOCRUZ, Salvador 40296-710, Brazil; petersen.swe@gmail.com (A.L.d.O.A.P.); beatrizrsdias@gmail.com (B.R.S.D.); luanabio@hotmail.com (L.C.P.); yasmindasilvaluz.1997@gmail.com (Y.d.S.L.); juliana.fullam@fiocruz.br (J.P.B.d.M.)

2 Wellcome Trust Centre for Molecular Parasitology, Institute of Infection, Immunity and Inflammation, College of Medical Veterinary and Life Sciences, University of Glasgow, Glasgow G12 8QQ, UK; bcull53@hotmail.com (B.C.); jeremy.mottram@york.ac.uk (J.C.M.)

3 Post-Graduate Program in Experimental Pathology, Federal University of Bahia (UFBA), Salvador 40110-909, Brazil

4 Department of Biology, York Biomedical Research Institute, University of York, York YO10 5DD, UK

5 National Institute of Tropical Disease (INCT-DT), National Council for Scientific and Technological Development (CNPq), Brasília 71605-001, DF, Brazil

* Correspondence: patricia.veras@fiocruz.br; Tel.: +55-(71)-3176-2263

check for updates

Citation: Petersen, A.L.d.O.A.; Cull, B.; Dias, B.R.S.; Palma, L.C.; Luz, Y.d.S.; de Menezes, J.P.B.; Mottram, J.C.; Veras, P.S.T. 17-AAG-Induced Activation of the Autophagic Pathway in Leishmania Is Associated with Parasite Death. Microorganisms 2021, 9, 1089. https://doi.org/ 10.3390/microorganisms 9051089

Academic Editor: Helena Castro

Received: 26 March 2021

Accepted: 23 April 2021

Published: 19 May 2021

Publisher's Note: MDPI stays neutral with regard to jurisdictional claims in published maps and institutional affiliations.

Copyright: (c) 2021 by the authors. Licensee MDPI, Basel, Switzerland. This article is an open access article distributed under the terms and conditions of the Creative Commons Attribution (CC BY) license (https:/ / creativecommons.org/licenses/by/ $4.0 /)$.

\begin{abstract}
The heat shock protein 90 (Hsp90) is thought to be an excellent drug target against parasitic diseases. The leishmanicidal effect of an Hsp90 inhibitor, 17-N-allylamino-17-demethoxygeldanamycin (17-AAG), was previously demonstrated in both in vitro and in vivo models of cutaneous leishmaniasis. Parasite death was shown to occur in association with severe ultrastructural alterations in Leishmania, suggestive of autophagic activation. We hypothesized that 17-AAG treatment results in the abnormal activation of the autophagic pathway, leading to parasite death. To elucidate this process, experiments were performed using transgenic parasites with GFP-ATG8-labelled autophagosomes. Mutant parasites treated with 17-AAG exhibited autophagosomes that did not entrap cargo, such as glycosomes, or fuse with lysosomes. ATG5-knockout ( $\triangle a t g 5)$ parasites, which are incapable of forming autophagosomes, demonstrated lower sensitivity to 17-AAG-induced cell death when compared to wild-type (WT) Leishmania, further supporting the role of autophagy in 17-AAG-induced cell death. In addition, Hsp90 inhibition resulted in greater accumulation of ubiquitylated proteins in both WT- and $\Delta a t g 5$-treated parasites compared to controls, in the absence of proteasome overload. In conjunction with previously described ultrastructural alterations, herein we present evidence that treatment with 17-AAG causes abnormal activation of the autophagic pathway, resulting in the formation of immature autophagosomes and, consequently, incidental parasite death.
\end{abstract}

Keywords: Hsp90; leishmaniasis; chemotherapy; Hsp90 inhibitors; autophagy; ubiquitin

\section{Introduction}

Leishmania spp. are protozoan parasites [1,2] that cause leishmaniasis, which can present in a variety of clinical manifestations, including skin and visceral forms [3]. Being one of the most important neglected tropical diseases, leishmaniasis affects millions of people worldwide. Financial investment in new therapeutic strategies has been scarce [3], resulting in pentavalent antimonials being the drug of choice for more than 70 years in Brazil. However, antimonial therapy requires parenteral administration at high dosage and involves a lengthy therapeutic course that can result in a range of serious side effects [4]. Recent increases in therapeutic failure [5-7] reinforce the importance of developing new drugs capable of replacing or complementing existing strategies for leishmaniasis treatment. 
Heat shock protein 90 (Hsp90) has been considered as a potential molecular target for the treatment of parasitic diseases [8-10]. Hsp90 inhibitors, such as geldanamycin or 17-N-allylamino-17-demethoxygeldanamycin (17-AAG), have demonstrated inhibitory effects on the differentiation process of Leishmania in vitro [11] and were shown to exert anti-parasitic activity in vitro and in vivo [12-16]. These inhibitors are members of a family of antibiotics that selectively bind to the Hsp90 ATP pocket, preventing ATP hydrolysis and folding of client proteins that do not achieve a tertiary structure. In mammals, these unfolded proteins are eventually degraded in the ubiquitin-proteasome system, which can result in cell death secondary to proteasome overload. This can subsequently lead to the formation of protein aggregates [17-20], resulting in the activation of a protective selective autophagic process in order to avoid aggregate accumulation in the cytoplasm [21-23]. Alternatively, Hsp90 inhibition can lead to a pronounced transcription of Hsp70, Hsp90 and Hsp40, responsible for mounting mis- or unfolded proteins, thereby limiting the formation of polyubiquitylated protein aggregates [24].

In previous studies, we have demonstrated that $17-\mathrm{AAG}$ was capable of controlling Leishmania infection (in vitro [15] and in vivo [16]) by eliminating promastigotes, which colonize the insect vector, as well as amastigotes, which are found within vertebrate host cells $[15,16]$. Nevertheless, the mechanism by which Hsp90 inhibition causes parasite death remains unclear. Electron microscopy revealed ultrastructural alterations suggestive of the activation of autophagy in parasites, including progressive cytoplasmic vacuolization, double-membrane vacuoles, myelin figures and vacuoles containing cytoplasmic material, all occurring in the absence of significant alterations in cellular nuclei, mitochondria or plasma membranes [15].

The conserved autophagic process in eukaryotic cells is responsible for the turnover of long-lived proteins and organelles inside autophagosomes $[25,26]$, which plays an important role in cellular homeostasis and in cell survival in response to different types of stress [25,27-29]. Autophagosomes are formed in successive steps involving the recruitment and activation of proteins of the ATG (AuTophaGy-related genes) family [30-32]. In Leishmania parasites, ATG12 must firstly conjugate with ATG5 in order for ATG8 to participate in the assembly of this complex, resulting in the formation of autophagosomes [33-35] that may acquire cargo and fuse with lysosomes, thereby forming autolysosomes [33,34]. The engulfed material is degraded, generating small molecules that may be utilized for cell survival $[36,37]$. Autophagy has also been identified as essential to the differentiation of Leishmania promastigotes into amastigotes [33]. By contrast, autophagic induction has been associated with death in eukaryotic cells $[30,38]$. Thus, the true role played by autophagy with respect to the mechanism responsible for causing protozoan parasite death in response to several stress stimuli, including antiparasitic drugs, remains to be elucidated [39].

We hypothesize that 17-AAG induces abnormal activation of autophagy in Leishmania spp., resulting in parasite death. To test this, several genes of the autophagic pathway were genetically modified in L. major promastigotes, which were used to investigate the participation of autophagy in parasite death following treatment with 17-AAG.

\section{Materials and Methods}

\subsection{Leishmania Culturing}

Leishmania major (MHOM/JL/80/Friedlin) were cultivated in modified HOMEM medium (Gibco, Carlsbad, CA, USA) supplemented with 10\% $(v / v)$ heat-inactivated fetal calf serum (Gibco) and 1\% (v/v) penicillin streptomycin solution (Sigma, St. Louis, MO, USA) at $25^{\circ} \mathrm{C}$ until mid-log phase was achieved, corresponding to $5 \times 10^{6}$ parasites $/ \mathrm{mL}$.

\subsection{Generation of Parasite Mutants Expressing Fluorescent Markers}

All mutant parasites used in this research were previously generated by our collaborators and are described as follows: (i) green fluorescent protein-ATG8 (GFP-ATG8) plasmid as described by Besteiro et al. [33]; (ii) the glycosome targeting SQL motif labelled with RFP plasmid (RFP-SQL) as described by Cull et al. [40]; (iii) the proCPB lysosomal-marker 
labeled with RFP plasmid (RFP-proCPB) by Huete-Perez et al. [41]. Null mutant atg5 parasites ( $\triangle a t g 5), \Delta a t g 5$ expressing GFP-ATG8 ( $\triangle a t g 5(G F P-A T G 8))$ and $\Delta a t g 5:: A T G 5$ parasites re-expressing ATG5 in the $\Delta a t g 5$ null mutant were generated by Williams et al. [35] and used as controls. In sum, two plasmids, both derived from pGL345-HYG, the pGL345ATG5HYG5 ${ }^{\prime} 3^{\prime}$ and pGL345ATG5-BLE5 ${ }^{\prime} 3^{\prime}$, were generated with fragments of the $5^{\prime}$ and $3^{\prime}$ UTRs flanking the ORF of ATG5 gene. The resulting linearized cassettes were used in two rounds of electroporation using a nucleofector transfection system according to the manufacturer's instructions (Lonza, Basel, Switzerland) to produce a heterozygous cell line, simultaneously resistant to hygromycin and bleomycin. To select the parasites that successfully expressed the desired proteins, an appropriate antibiotic was used to treat each transfected parasite line: G418 (Neomycin) at $50 \mu \mathrm{g} / \mathrm{mL}$; Hygromycin at $50 \mu \mathrm{g} / \mathrm{mL}$; Blasticidin S at $10 \mu \mathrm{g} / \mathrm{mL}$; Phleomycin at $10 \mu \mathrm{g} / \mathrm{mL}$ (all from InvivoGen, San Diego, CA, USA).

\subsection{Parasite Treatment with $17-A A G$ or Pentamidine}

In accordance with each experimental protocol, promastigotes of $L$. major were submitted to treatment procedures using the antileishmanial 17-AAG (InvivoGen, San Diego, CA, USA) $(100,300$ or $500 \mathrm{nM})$ or pentamidine (Sigma, St. Louis, MO, USA) (10, 20 and $30 \mu \mathrm{M})$ for up to $72 \mathrm{~h}$. At the end of each treatment period, parasites were pelleted by centrifugation for $3 \mathrm{~min}$ at $1000 \times g$ and then washed thrice in PBS for medium removal. Cells were then resuspended in PBS and a $10 \mu \mathrm{L}$ suspension was spread thinly over a slide covered with a $22 \times 40 \mathrm{~mm}$ coverslip, then sealed with nail varnish to perform fluorescence microscopy.

2.4. Assessment of Autophagosome Formation and Autophagosome Colocalization with Glycosomes and Lysosomes by Fluorescence Microscopy

Fluorescence microscopy was used: (i) to assess the presence of GFP-ATG8-labelled vesicles, characteristic of autophagosomes, which appear as punctate structures as previously described [40,42] and (ii) to evaluate the effects of 17-AAG treatment on the autophagosomal maturation process using the two L. major double-mutant promastigotes: GFP-ATG8 and RFP-SQL; GFP-ATG8 and proCPB-RFP. To quantify the number of GFP-ATG8-labelled vesicles and determine the percentage of parasites containing GFPATG8-labelled vesicles, after mounting for up to $1 \mathrm{~h}$, parasite smears were observed under a DeltaVision Core deconvolution microscope (Applied Precision Inc., Issaquah, WA, USA) using GFP or mCherry filters at 1,000 magnification. For cell visualization, DIC images were also obtained under polarized light. All images were processed and analyzed using SoftWoRx image analysis software (Applied Precision Inc.) [40,42]. At least 300 parasites were counted for each combination of treatment and time point, with no less than three independent experiments considered. Also, the effects of 17-AAG treatment on the autophagosomal maturation process was evaluated in the double-mutant L. major promastigotes. Autophagosome colocalization with glycosomal cargo or with lysosomes was evaluated after treatment with $500 \mathrm{nM}$ of $17-\mathrm{AAG}$ at 24 or $48 \mathrm{~h}$. Parasites were also imaged using a DeltaVision Core deconvolution microscope as described above. Images were submitted to colocalization analysis using SoftWoRx image analysis as previously described [43].

\subsection{Parasite Viability}

Axenic parasites in mid-log phase were treated with serial dilutions of 17-AAG for $48 \mathrm{~h}$ at concentrations ranging from 10 to $15,625 \mathrm{nM}$ or with DMSO (control), and after adding AlamarBlue (Invitrogen, Carlsbad, CA, USA) (10\% final concentration) followed by incubation for another $24 \mathrm{~h}$ at $24{ }^{\circ} \mathrm{C}$, reagent absorbance was measured at the wavelengths of 570 and $600 \mathrm{~nm}$.

To evaluate the kinetics of 17-AAG on the viability of $\triangle \operatorname{atg} 5$ compared to WT and $\Delta$ atg5::ATG5 parasites, promastigote cultures were treated with $300 \mathrm{nM}$ and $500 \mathrm{nM}$ of the Hsp90 inhibitor for $24 \mathrm{~h}, 48 \mathrm{~h}$ and $72 \mathrm{~h}$ at $24^{\circ} \mathrm{C}$. AlamarBlue was added and absorbance was measured as described above. Treatment effect was estimated by determining the area under the curve (AUC) for each group. 


\subsection{Parasite Growth Curve}

Leishmania cell lines (WT, $\Delta a t g 5$ and $\triangle a t g 5:: A T G 5)$ at a concentration of $10^{5}$ cells $/ \mathrm{mL}$ were incubated in $10 \mathrm{~mL}$ of HOMEM medium supplemented with $10 \%(v / v)$ heat-inactivated fetal calf serum and $1 \%(v / v)$ penicillin streptomycin solution. Cells were treated or not with $100 \mathrm{nM}$ of $17-\mathrm{AAG}$ and counts were performed daily for at least 13 days. Parasite numbers were recorded and plotted.

\subsection{Western Blot to Assess Ubiquitylated Proteins}

The accumulation of ubiquitylated proteins in parasites treated with 17-AAG $(500 \mathrm{nM})$ for $24 \mathrm{~h}$ was evaluated by Western blot analysis. As a positive control, parasites were treated with the proteasome inhibitor MG132 $(3 \mu \mathrm{M})$ for $24 \mathrm{~h}$. Following treatment, parasites were pelleted by centrifugation for $3 \mathrm{~min}$ at $1000 \times g$, and then washed thrice in PBS for medium removal. Protein extraction was then performed for Western blot analysis as described below.

Parasites were lysed with laemmli buffer (2-Mercaptoethanol $0.1 \%$, bromophenol blue $0.0005 \%$, glycerol $10 \%$, SDS $2 \%$, Tris- $\mathrm{HCl} 63 \mathrm{mM}, \mathrm{pH} 6.8$ ) at a proportion of $10 \mu \mathrm{L}$ of buffer for $10^{6}$ parasites, then boiled for $5 \mathrm{~min}$ and cell extracts were stored at $-20^{\circ} \mathrm{C}$. Proteins were transferred from a $12 \%$ polyacrylamide gel, following electrophoresis, to a HybondC nitrocellulose membrane (Amersham, GE Healthcare, Little Chalfont, UK). Transfer was carried out by semi-dry blotting using a BioRad Trans-Blot SD Semi-Dry Transfer Cell at 30 volts for $45 \mathrm{~min}$, with membranes and filter papers soaked in transfer buffer (20 mM Tris-HCl, $15 \mathrm{mM}$ glycine, 20\% (v/v) methanol, in distilled water). Membranes were subsequently incubated in a blocking solution for $1 \mathrm{~h}$ at room temperature or overnight at $4{ }^{\circ} \mathrm{C}$ under agitation. After blocking, each membrane was incubated with 1:1000 FK2 anti-ubiquitin antibody (LifeSensors, Malvern, PA, USA) diluted in fresh TBST buffer with $3 \%$ milk for $1 \mathrm{~h}$ at room temperature. Secondary anti-mouse antibody conjugated with horseradish peroxidase (HRP) (Promega, Madison, WI, USA) was diluted at 1:10,000 in fresh TBST buffer and each membrane was first incubated with an ECL (Enhanced Chemiluminescence) solution (SuperSignal West Pico Chemiluminescent Substrate Kit, Pierce, Rockford, IL, USA), and then exposed on Kodak photographic film. An antibody against elongation factor $1 \alpha$ (EF1 $\alpha$ ) (Millipore, Germany) was used for loading control. Western blotting experiments were performed three times.

\subsection{Assessment of Protein Aggregation}

Axenic promastigotes of L. major lines (WT, $\Delta a t g 5$ and $\Delta a t g 5:: A T G 5)$ were treated with 17-AAG $(500 \mathrm{nM})$ or MG132 $(3 \mu \mathrm{M})$ for $24 \mathrm{~h}$ at $24{ }^{\circ} \mathrm{C}$. The aggregation of soluble proteins was analyzed following a previously described protocol [44] employing SDSPAGE. Briefly, $3 \times 10^{8}$ parasites were centrifuged at $1800 \times g$ at $4{ }^{\circ} \mathrm{C}$ for $10 \mathrm{~min}$. The pellet was resuspended in $500 \mu \mathrm{L}$ of lysis buffer $(50 \mathrm{mM}$ potassium phosphate buffer, $1 \mathrm{mM}$ EDTA, $5 \%$ glycerol, $1 \mathrm{mM}$ protease inhibitor, Roche, Mannheim, Germany) and submitted to a 5 freeze-thaw cycles (liquid nitrogen-water). Intact cells were removed by centrifugation at $1800 \times g$ for $5 \mathrm{~min}$ and proteins were quantified. Then, $1 \mathrm{mg}$ of protein from each group was centrifuged at $15,000 \times g$ for $20 \mathrm{~min}$ to isolate the membrane and aggregate fractions. Next, pellets were resuspended in lysis buffer, then sonicated and membrane proteins were removed via the addition of $2 \%$ NP40 followed by centrifugation at $15,000 \times g$ for $20 \mathrm{~min}$. Pellets were resuspended in $100 \mu \mathrm{L}$ of SDS sample buffer and heated at $95^{\circ} \mathrm{C}$ for $5 \mathrm{~min}$. Samples were then analyzed using 10\% SDS-PAGE, followed by silver labeling using a Bio-Rad Silver Stain kit (Bio-Rad, Hercules, CA, USA) in accordance with the manufacturer's instructions. Experiments were independently repeated three times.

\subsection{Statistical Analysis}

The half maximal inhibitory concentration ( $\mathrm{IC}_{50}$ ) of 17-AAG in L. major WT, $\triangle$ atg5 and $\triangle a t g 5:: A T G 5$ promastigotes was determined by performing sigmoidal regression on each respective concentration-response curve. Data are presented as the mean \pm 
standard deviation of the mean under parametric analysis (One-way ANOVA or Welch's ANOVA test followed by Tukey's or Dunnett's Multiple Comparisons) or medians and quartile ranges in the case of non-parametric analysis (Kruskal-Wallis test, Dunn's multiple comparison). All data were analyzed using the Prism program (GraphPad software, V. 9.1.0 La Jolla, CA, USA).

\section{Results}

\subsection{7-AAG Induces Autophagosome Formation in Promastigote Forms of Leishmania}

Treatment of Leishmania parasites with 17-AAG at the concentration of $500 \mathrm{nM}$ resulted in an increased number of parasites containing green-labeled punctate structures (Figure 1A). After $48 \mathrm{~h}$ of treatment at both 300 and $500 \mathrm{nM}$, among counted parasites, 33.1\% (Q1: 29.3; Q3: 33.9) and 37.4\% (Q1: 34.7; Q3: 37.8, $p<0.05)$, respectively, of parasites contained punctate structures, while these alterations were seen in only $19.2 \%(\mathrm{Q} 1: 17.2$; Q3: 21.1) of control parasites (Figure $1 \mathrm{~B} ; p<0.05$ ). This percentage of L. major promastigotes containing punctate structures increased after $72 \mathrm{~h}$ of treatment, with a median value of 36.1\% (Q1: 32.1; Q3: 44.4) of the parasites treated with $300 \mathrm{nM}$ and 50.2\% (Q1: 43.5; Q3: $55.2, p<0.05)$ of those treated with $500 \mathrm{nM}$ revealing labeled vesicles in the cytosol, while the level of control parasites containing punctate structures was $20.1 \%$ (Q1: 18.3 ; Q3: 22.6) at $72 \mathrm{~h}$ of treatment (Figure $1 \mathrm{~B}$ ). The median values of the number of punctate structures in parasites treated with $300 \mathrm{nM}$ of 17-AAG at 48 and $72 \mathrm{~h}$ were not statistically different compared to diluent-treated L. major promastigotes. The median number of GFPATG8-labeled vesicles per parasite after 48 and $72 \mathrm{~h}$ was higher in parasites treated with $500 \mathrm{nM}$ of 17-AAG, with values of 1.8 (Q1: 1.7;Q3:1.8, $p<0.05)$ and 2.0 (Q1: 1.8; Q3: 2.2), respectively, compared to median values of $1.4(\mathrm{Q} 1: 1.2 ; \mathrm{Q} 3: 1.5, p<0.05)$ and $1.2(\mathrm{Q} 1: 1.2$; Q3: 1.4) (Figure 1B) in control parasites. The atg5-deficient parasites expressing GFP-ATG8 ( $\triangle$ atg5(GFP-ATG8)) treated with 17-AAG exhibited no fluorescent punctate structures, confirming that the vesicles detected in GFP-ATG8 parasites were indeed autophagosomes (Figure 1C). As an additional control, parasites were treated with another antileishmanial, pentamidine, at concentrations of 10,20 or $30 \mu \mathrm{M}$ for 24,48 and $72 \mathrm{~h}$. Treatment with pentamidine caused cell death (data not shown), yet few punctate structures were detected in the cytosol of treated parasites (Figure 1D). This indicates that parasite death is not always associated with autophagosome formation in Leishmania parasites.

\subsection{7-AAG Inhibits the Autophagosome Maturation Process}

Since the inhibition of endosome and autophagosome fusion with lysosomes by chloroquine has been previously shown to be involved in parasite death [45-47], we investigated whether treatment with 17-AAG was capable of altering the autophagosomal maturation process. In double-mutant parasites expressing GFP-ATG8 and the glycosomal marker, RFP-SQL, a mean value of $22.7 \% \pm 4.4$ of the total number of counted autophagosomes colocalized with glycosomes in parasites treated with 17-AAG (500 nM, $24 \mathrm{~h}$ ), similar to untreated double-mutant parasites $(30.5 \% \pm 6.4)$ (Figure $2 \mathrm{~A}, \mathrm{~B})$. After $48 \mathrm{~h}$ of treatment, a comparable proportion of colocalization was observed in labeled compartments $(20.5 \% \pm 3.9)$ in treated parasites, which was significantly lower than that detected in control parasites treated with DMSO, 41.6\% \pm 5.2 (Figure 2A,B; $p=0.0006$ ). Additionally, double-mutant parasites expressing both GFP-ATG8 and the lysosomal marker, proCPBRFP, when treated with 17-AAG (500 nM) for 24 and $48 \mathrm{~h}$, exhibited a remarkably lower proportion of autophagosome-lysosome colocalization after $24 \mathrm{~h}$, with mean values of $8.2 \% \pm 5.1(p=0.0197)$ and $48 \mathrm{~h}, 12.1 \% \pm 11.6$, in comparison to DMSO-treated controls: $35.6 \% \pm 16.6$ and $38.6 \% \pm 25.6$, respectively (Figure $2 \mathrm{C}, \mathrm{D}$ ). These findings indicate that 17-AAG treatment resulted in inhibition of the autophagosome maturation process via fusion inhibition of ATG8-labelled vesicles with compartments labelled with lysosomal and glycosomal markers. 

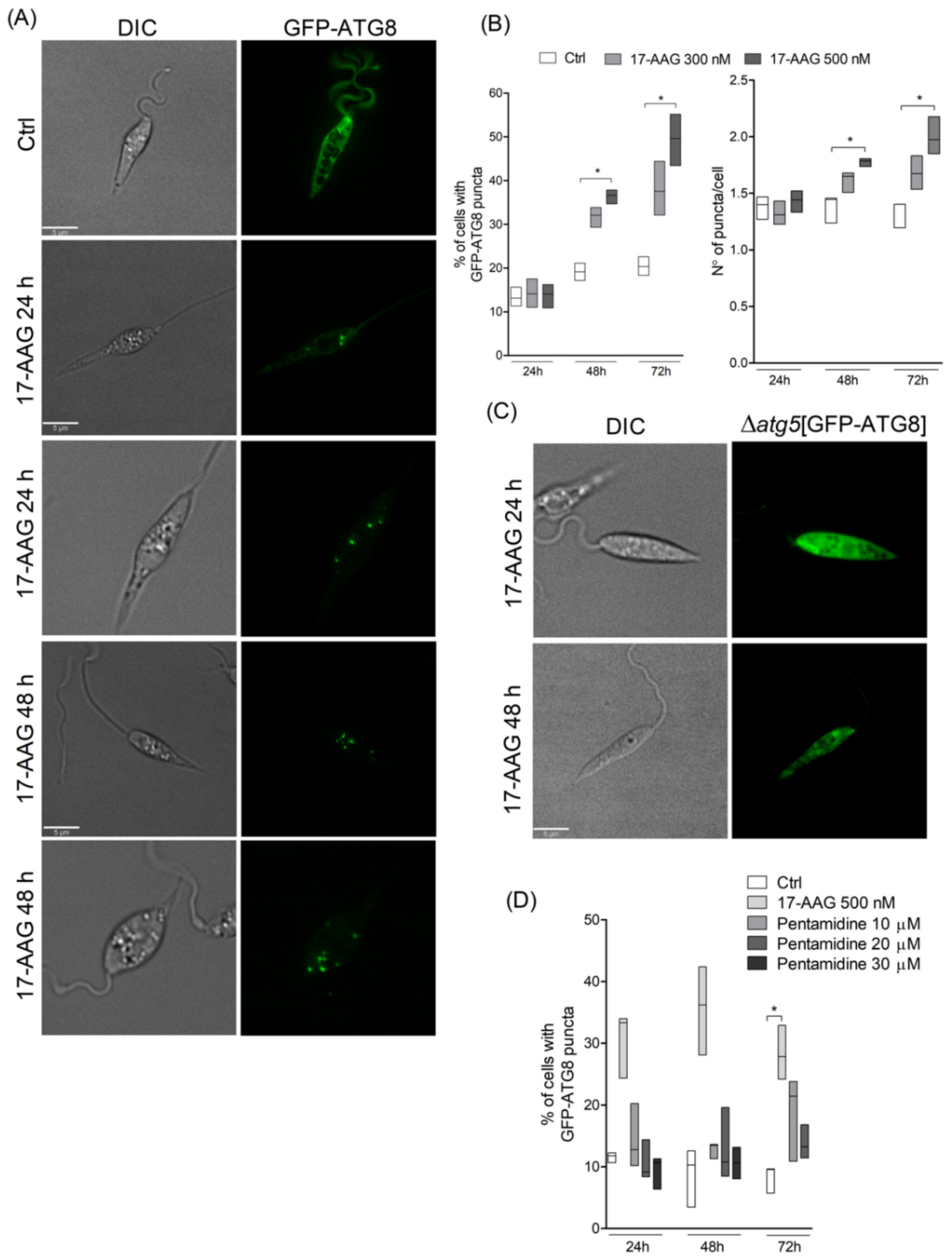

Figure 1. Evaluation of autophagosome formation in Leishmania promastigotes following treatment with 17-AAG. (A) Axenic promastigotes of Leishmania expressing GFP-ATG8 were treated or not with 17-AAG (500 nM) for 24 or $48 \mathrm{~h}$ and imaged by fluorescence microscopy. (B) The percentage of cells bearing autophagosomes and the number of autophagosomes per cell were calculated at 24, 48 and $72 \mathrm{~h}$ after treatment with 17-AAG (300 or $500 \mathrm{nM}$ ). (C) $\triangle$ atg5[GFP-ATG8] parasites were treated with 17-AAG and imaged by fluorescence microscopy. (D) Comparison of the percentage of cells bearing autophagosomes after treatment with pentamidine $(10,20$ or $30 \mu \mathrm{M})$ or 17-AAG $(500 \mathrm{nM})$ for 24 and $48 \mathrm{~h}$. Lines within the floating bars represent medians and floating bar quartiles (Q: $25 \%$ and $75 \%$ ) from one out of three independent experiments (Kruskal-Wallis test, Dunn's multiple comparison test, $\left.{ }^{*} p<0.05\right)$. 


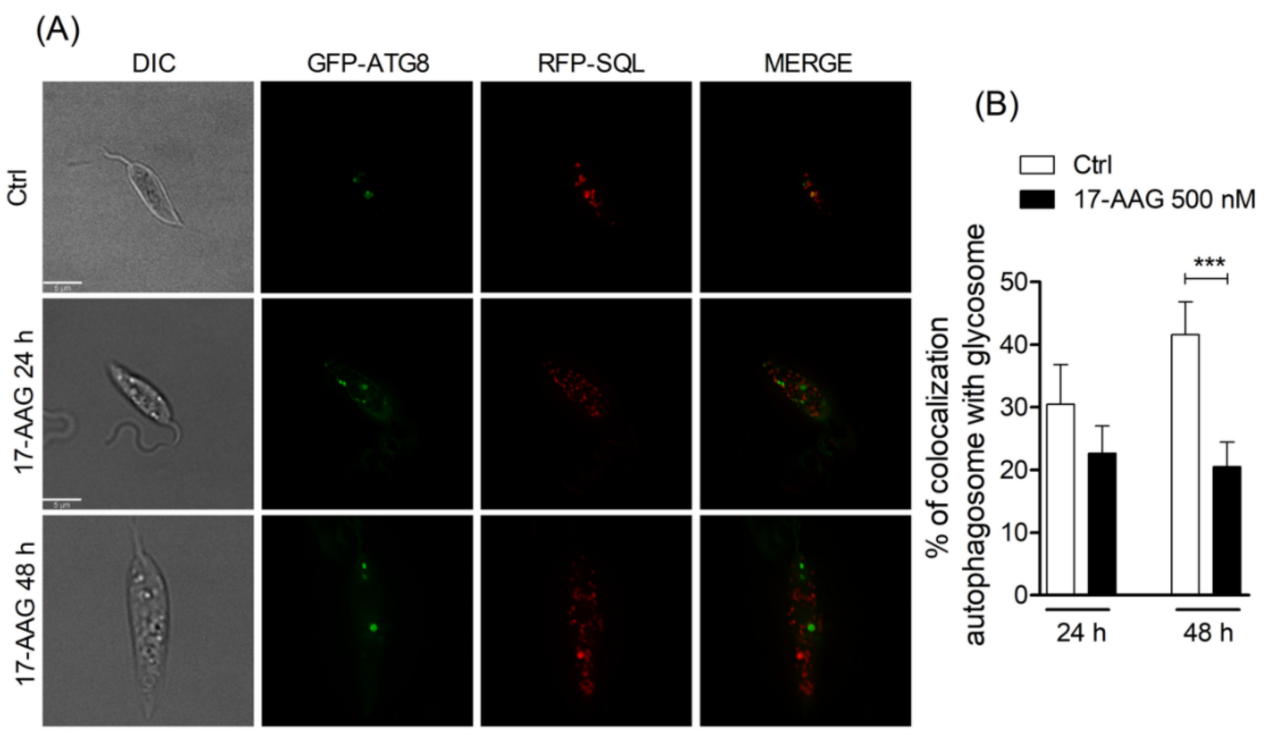

(C)
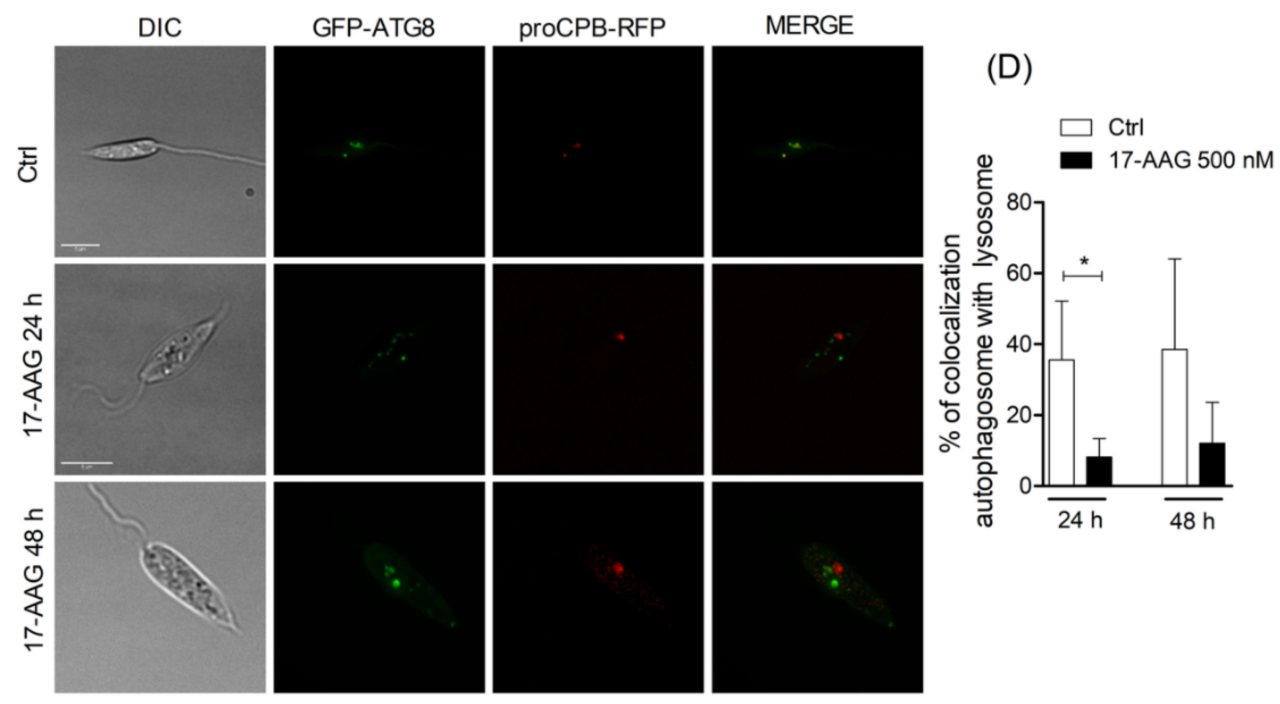

Figure 2. Analysis of fusion between autophagosomes and glycosomes or lysosomes. (A) Axenic promastigotes of Leishmania expressing GFP-ATG8 and RFP-SQL were treated or not with 17-AAG (500 nM) and imaged by fluorescence microscopy. (B) Quantification of autophagosome-glycosome colocalization after treatment of Leishmania with 17-AAG. (C) Axenic promastigotes of Leishmania expressing ATG8-GFP and proCPB-RFP were treated or not with 17-AAG (500 nM) and imaged by fluorescence microscopy. (D) Quantification of Leishmania autophagosome-lysosome colocalization after treatment with 17-AAG. Bars represent medians $\pm \mathrm{SD}$ from one out of three independent experiments (Unpaired $\mathrm{t}$ test, ${ }^{* * *} p=0.0006$, $* p=0.0197)$.

\section{3. atg5-Deficient Parasites Are More Resistant to 17-AAG-Induced Cell Death Than WT Parasites}

To evaluate whether autophagy plays a role in 17-AAG-induced parasite death, $\mathrm{IC}_{50}$ values were determined for $\Delta a t g 5$ parasites treated with $17-\mathrm{AAG}$ for $48 \mathrm{~h}$, which showed a mean value of $174.3 \mathrm{nM} \pm 15.7,83.7 \%$ higher than that determined for WT (Figure 3A, $p<0.01$ ). Moreover, when the atg 5 gene was added back to the $\triangle a t g 5$ parasites ( $\triangle$ atg5::ATG5), the resulting $\mathrm{IC}_{50}$ value was $104.3 \mathrm{nM} \pm 32.9$, similar to that found in WT L. major promastigotes $(95.0 \mathrm{nM} \pm 23.1)$ (Figure 3A, $p<0.01$ ). In addition, when cultivated in medium containing $100 \mathrm{nM}$ of $17-\mathrm{AAG}$ for 13 days, $\Delta a \operatorname{tg} 5$ parasites grew faster than either WT or $\Delta a t g 5:$ ATG5, as assessed by growth curves (Figure 3B) and the area under 
the curve (AUC) (Figure 3C). This marked growth was especially noticeable during the log growth phase (days 5-6) when $500 \%$ more $\triangle a t g 5$ parasites were seen compared to WT or $\triangle a t g 5:: A T G 5$ (Figure 3B). In contrast, no differences in parasite growth rates were observed among these three parasite lines when cultivated in 17-AAG-free medium (Figure 3B). Even when the highest concentrations of 17-AAG (300 and $500 \mathrm{nM}$ ) were administered to promastigotes for up to $72 \mathrm{~h}$, less toxicity was evidenced in the $\Delta a t g 5$ lineage compared to WT or $\triangle a t g 5:: A T G 5$ L. major parasites (Figure 3D). These findings provide evidence that $\triangle a t g 5$ parasites are less susceptible to cell death following treatment with 17-AAG, which suggests the participation of autophagy in inhibitor-induced parasite death.

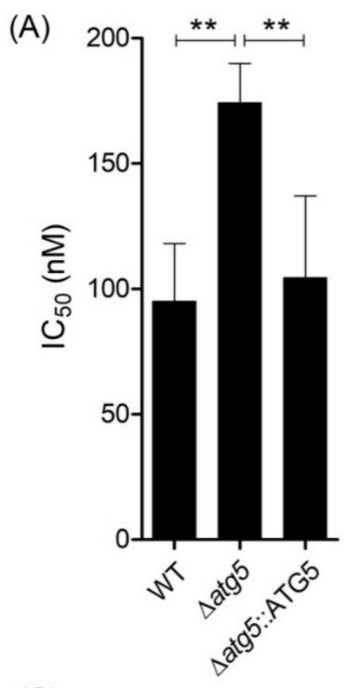

(C)

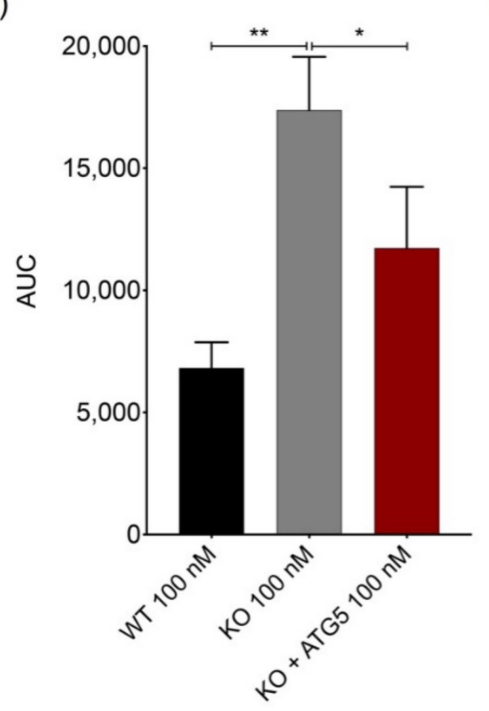

(B)

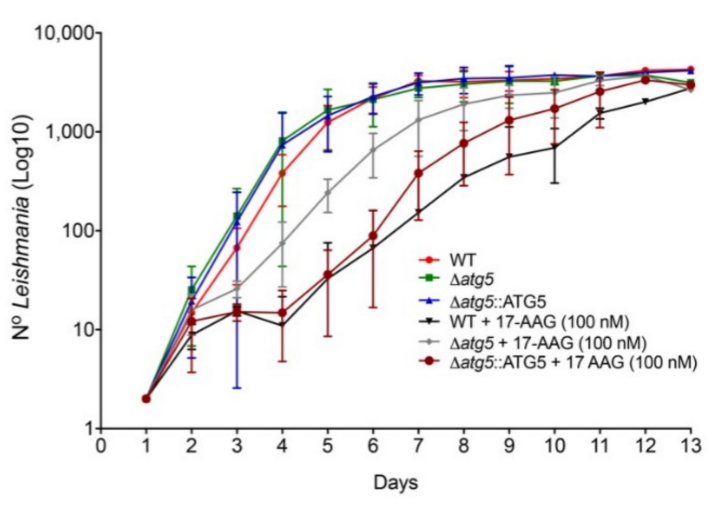

(D)

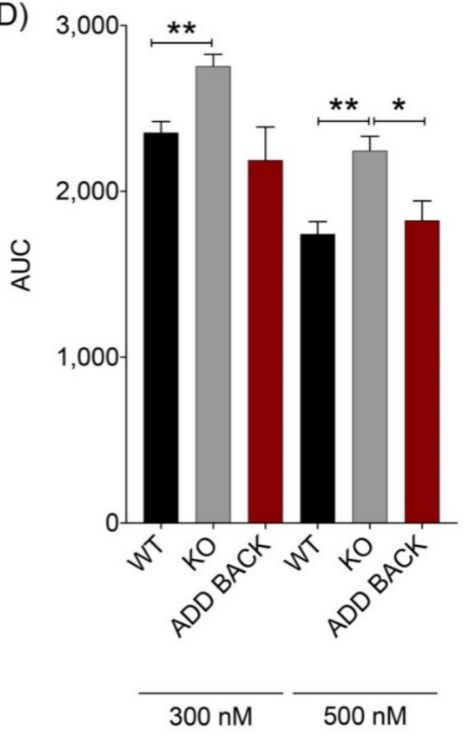

Figure 3. Effect of 17-AAG on survival and replication of WT, $\operatorname{atg} 5$ and $\triangle a t g 5:: A T G 5$ Leishmania. (A) $\mathrm{IC}_{50}$ values for 17-AAG in different Leishmania lineages. Bars represent mean $\pm \mathrm{SD}$ from four independent experiments (One-way ANOVA, Tukey's multiple comparisons test, ${ }^{* *} p<0.01$ ). (B) Growth curve reflecting 13 day-counts of WT, $\triangle a t g 5$ and $\triangle a t g 5$ ::ATG5 parasites, treated or not with 17-AAG at $100 \mathrm{nM}$. Symbols are representative of means \pm SD from three independent experiments. (C) Area under the curve (AUC) analysis of WT, $\triangle \operatorname{atg} 5$ and $\triangle a t g 5:: A T G 5$ growth depicted in panel (B), following treatment with 17-AAG. Bars represent mean \pm SD from three independent experiments (one-way ANOVA test, Tukey's multiple comparison test ${ }^{*} p=0.03210 .05,{ }^{* *} p=0.0016$ ). (D) AUC analysis of WT, $\triangle a t g 5$ and $\triangle a t g 5:: A T G 5$ viability following treatment with 17-AAG at $300 \mathrm{nM}$ and $500 \mathrm{nM}$ for $24 \mathrm{~h}, 48 \mathrm{~h}$ and $72 \mathrm{~h}$. Bars represent mean $\pm \mathrm{SD}$ of a single experiment performed in quadruplicate (Welch's ANOVA test, Dunnett's T3 multiple comparison test ${ }^{*} p<0.05,{ }^{* *} p<0.01$ ). 
3.4. 17-AAG Treatment Results in Increased Accumulation of Ubiquitylated Proteins, but Not Protein Aggregates, in L. major Parasites

Due to the participation of autophagy in Leishmania death arising from 17-AAG treatment, we hypothesized that autophagic activation could be consequent to Hsp90 inhibition, which causes a subsequent enhancement in the amount of ubiquitylated protein. Low basal levels of ubiquitylated proteins were seen in all untreated WT, $\Delta a t g 5$ and $\Delta$ atg5::ATG5 parasites (Figure 4). Treatment with 17-AAG ( $500 \mathrm{nM}$ for $48 \mathrm{~h}$ ) induced an overall increase in the amounts of ubiquitin-labeled proteins in WT, $\triangle$ atg5 and $\triangle$ atg5::ATG5 parasites (Figure 4). A similar result was observed after $48 \mathrm{~h}$ of 17-AAG treatment (data not shown). As expected, of the three lines evaluated, $\triangle a t g 5$ parasites demonstrated the greatest accumulation of ubiquitylated proteins after treatment with either $500 \mathrm{nM}$ of 17-AAG or $3 \mu \mathrm{M}$ of MG132 (Figure 4). Predictably, the treatment of parasites with MG132 (3 $\mu \mathrm{M}, 48 \mathrm{~h})$ increased the accumulation of ubiquitylated proteins in all three parasite lines evaluated. Moreover, treatment with MG132 also resulted in a higher proportion of autophagosomes in GFP-ATG8 parasites, as evidenced by the mean percentage of parasites bearing punctate structures: $14.7 \% \pm 3.5$ in parasites treated for $24 \mathrm{~h}$ with $3 \mu \mathrm{M}$ of MG132, in comparison to a mean value of $10.9 \% \pm 1.5$ in control parasites (Figure $5 \mathrm{~A}, \mathrm{~B}$ ). This difference increased at $48 \mathrm{~h}$ to $30.6 \% \pm 4.6$ of parasites treated with $3 \mu \mathrm{M}$ of MG132 compared to $6.8 \% \pm 2.0$ in controls (Figure $5 \mathrm{~B}, p=0.0007$ ). As was also expected, positive controls treated with $500 \mathrm{nM}$ of 17-AAG exhibited a significant increase in the percentage of parasites containing labeled vesicles: $20.8 \% \pm 1.3(p=0.0035)$ at $24 \mathrm{~h}$ and $21.1 \% \pm 4.3$ at $48 \mathrm{~h}(p=0.0091)$ (Figure $5 \mathrm{~B})$. Increased ubiquitylated protein accumulation can result in proteasomal overload and the accumulation of protein aggregates or, alternatively, enhancement in the transcription of Hsp70, Hsp90 and Hsp40 [48].

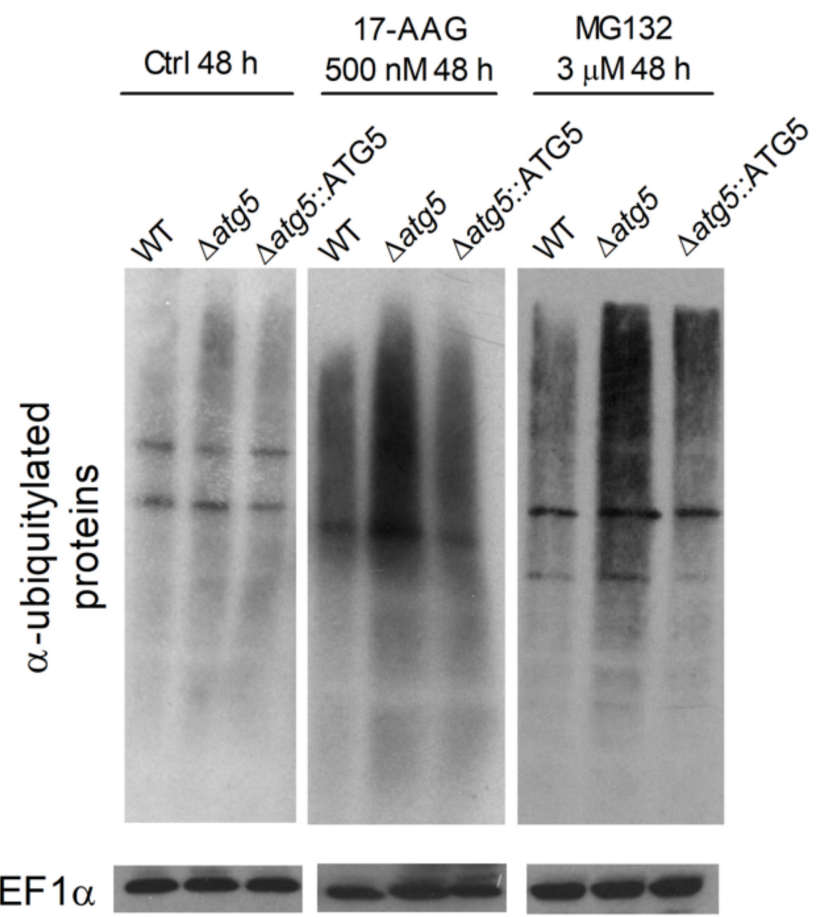

Figure 4. Ubiquitylated protein profiles of WT, $\triangle$ atg 5 and $\triangle a t g 5:: A T G 5$ after 17-AAG or MG132 treatment. WT, $\triangle a t g 5$ and $\triangle a t g 5:: A T G 5$ parasites were treated with 17-AAG $(500 \mathrm{nM})$ or MG132 $(3 \mu \mathrm{M})$ for $48 \mathrm{~h}$. Protein extracts were electrophoresed on a $12 \%$ gel, blotted and probed with an FK2 anti-ubiquitin antibody. EF1 $\alpha$ was used as loading control. 


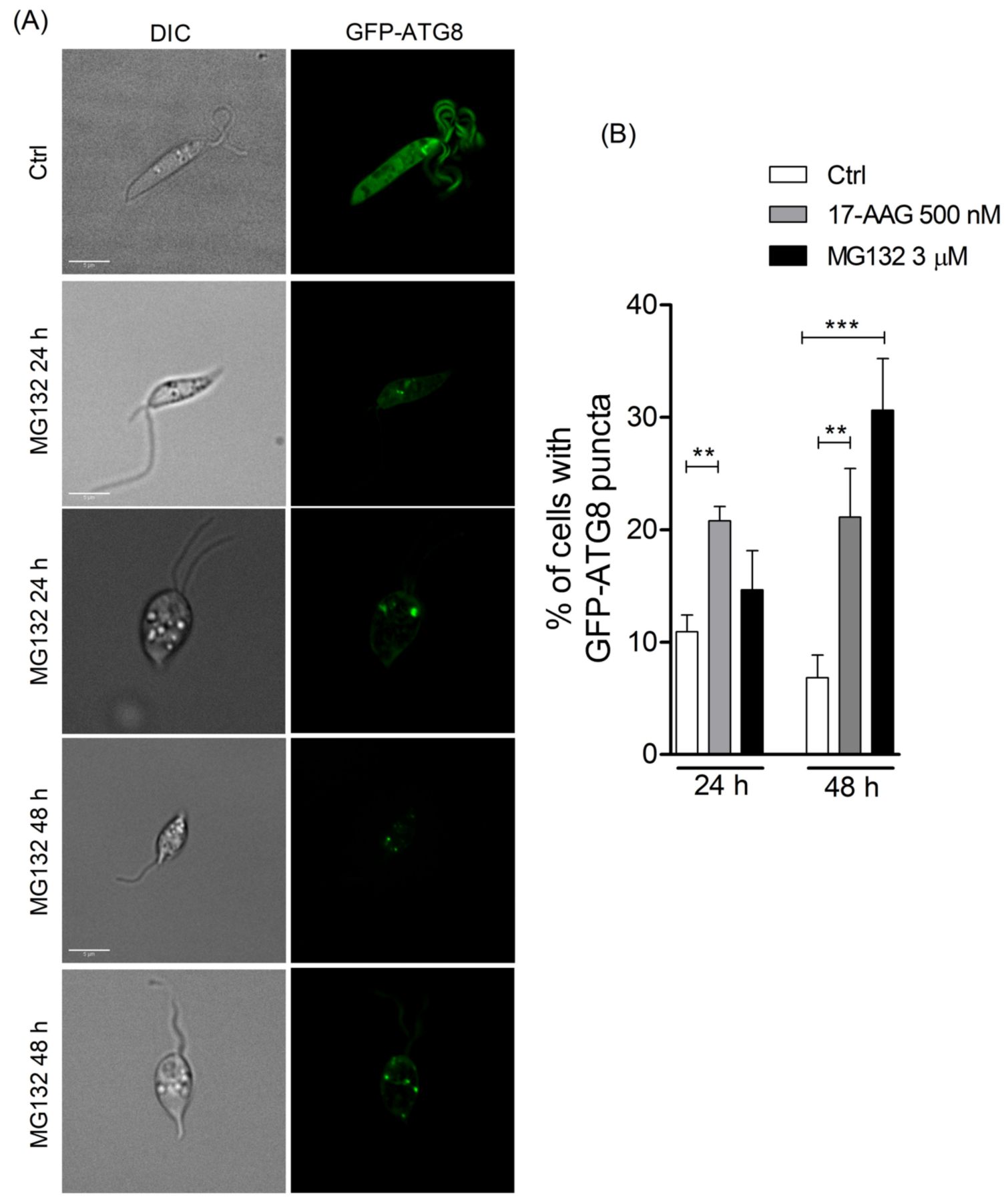

Figure 5. Evaluation of autophagosome formation in promastigotes of Leishmania following treatment with MG132. (A) Promastigotes of Leishmania expressing GFP-ATG8 were treated or not with MG132 $(3 \mu \mathrm{M})$ and imaged by fluorescence microscopy. (B) The percentage of cells bearing autophagosomes was calculated after treatment with 17-AAG (500 nM) or MG132 $(3 \mu \mathrm{M})$ for 24 and $48 \mathrm{~h}$. Bars represent mean \pm SD of three independent experiments (One-way ANOVA, Tukey's multiple comparisons test, $\left.{ }^{* *} p<0.01,{ }^{* * *} p<0.001\right)$.

Using SDS-PAGE, protein extracts of all parasite strains: WT, $\triangle$ atg5 and $\Delta a t g 5:: A T G 5$ treated with 17-AAG (500 $\mathrm{nM}$ for $24 \mathrm{~h}$ ) did not result in increased protein aggregate formation in comparison to untreated parasites, while positive control parasites treated with MG132 (3 $\mu \mathrm{M}$ for $24 \mathrm{~h}$ ) revealed increased amounts of protein aggregates (Figure 6). 


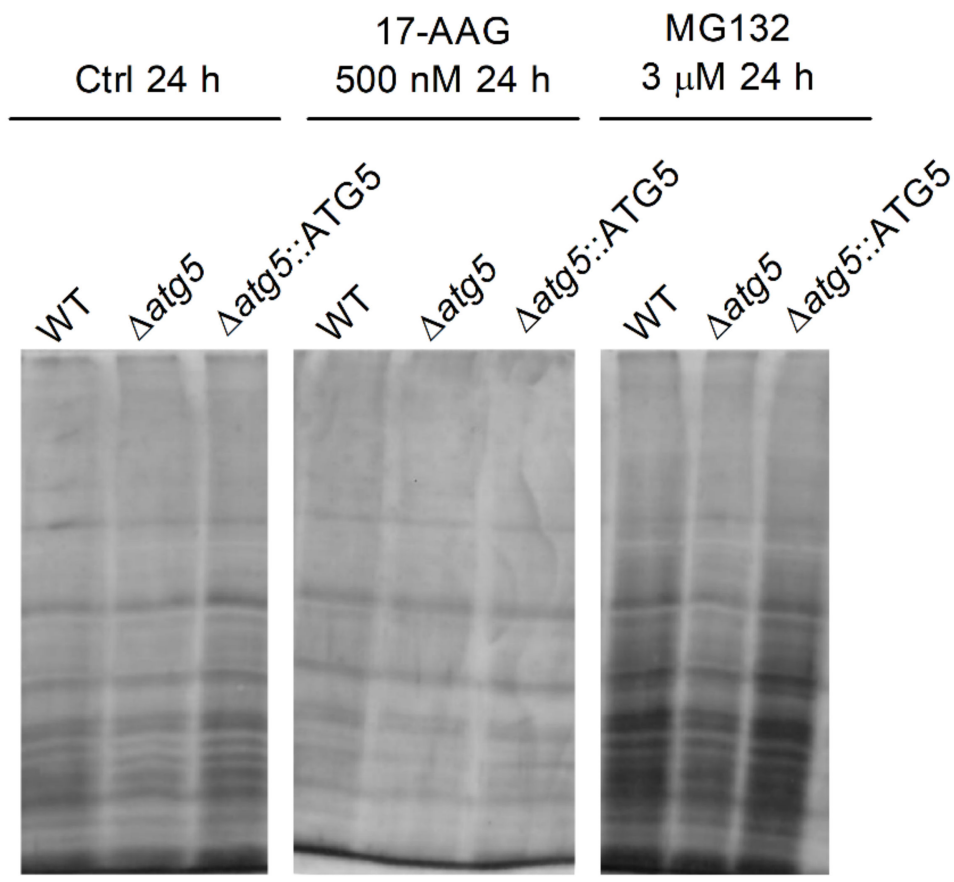

Figure 6. Effect of 17-AAG treatment on WT, $\triangle$ atg 5 and $\triangle \operatorname{atg} 5:$ :ATG5 protein aggregate formation. Culture aliquots from WT, $\Delta a t g 5$ and $\Delta a t g 5:: A T G 5$ parasites treated with 17-AAG (500 nM) or MG132 $(3 \mu \mathrm{M})$ for $24 \mathrm{~h}$ were withdrawn and analyzed to determine quantities of insoluble protein aggregates by cell lysis and centrifugation. Protein aggregates were subjected to SDS-PAGE followed by silver staining. One experiment is representative of two independent experiments.

\section{Discussion}

The present study confirmed that in Leishmania treated with 17-AAG, autophagy is induced by an increased percentage of autophagosomes expressing GFP-ATG8, as well as higher overall numbers of labeled autophagosomes per parasite. We also found that the macroautophagy-deficient $\triangle a t g 5[G F P-A T G 8]$ Leishmania, which is unable to form autophagosomes, did not form any detectable punctate structures.

The present study also found that treatment with 17-AAG induced a reduction in the degree of colocalization between autophagosomes and glycosomes, as well as between autophagosomes and lysosomes, in comparison to controls. Hsp90 is known to control the expression of hundreds of proteins involved in diverse cell functions [49,50]. A previous report described the involvement of Hsp90 in controlling vesicle trafficking and fusion by folding proteins, responsible for recycling RAB proteins from vesicle membranes back into the cytoplasm [51] and vesicle transport proteins that play a role in the transport of glycoproteins from the Golgi to other compartments [52]. Since reduced colocalization of the proCPB-RFP and GFP-ATG8 was observed in Leishmania following treatment with 17-AAG compared to untreated parasites, we speculate that Hsp90 inhibition results in the unfolding or incorrect folding of parasite proteins involved in vesicle trafficking and fusion. The inhibition of the fusion of newly-formed autophagosomes with lysosomes could result in the trapping of proteins and organelles within autophagosomes, leading to parasite death. In agreement with our findings, a recent study described that disrupting a cysteine protease located in the vacuolar compartment (VAC) of Toxoplasma gondii caused a reduction in the proteolytic activity of parasite lysosomes, the accumulation of undigested autophagosomes in parasite cytoplasm, and subsequently, a reduction in the intensity of infection [53].

We found that survival in $\Delta a t g 5 \mathrm{~L}$. major promastigotes increased compared to WT parasites under treatment with $17-\mathrm{AAG}$. Indeed, we showed that $\triangle$ atg 5 L. major were not only able to survive and proliferate more efficiently than WT at a low dosage of 17-AAG $(100 \mathrm{nM})$ for 13 days, but were also found to be more resistant to death at higher dosages 
(300 and $500 \mathrm{nM}$ ). These findings lead us to propose that the activation of the autophagic pathway contributes to Leishmania cell death. Macroautophagy is a successful adaptive strategy that functions as a protective mechanism activated under different physiological stress stimuli [54-56]. Similarly to our study, it has been shown that autophagy is induced in $T$. gondii in response to endoplasmic reticulum stress, followed by the accumulation of unfolded proteins [57]. Also, incomplete autophagosome maturation was shown to be harmful to eukaryotic cells [58], including mammals [48,59] and T. gondii [53]. Moreover, it was previously demonstrated that several Leishmania lines present an inability to complete the transformation process from promastigotes to amastigotes, including $\triangle a t g 5$ parasites [35], $\triangle$ atg 4.2 parasites expressing a mutant vesicular sorting protein 4 [33] form autophagosomes that do not fuse with lysosomes, and $\Delta c p a / c p b$ parasites, which do form autophagosomes that fuse with lysosomes, produce non-degraded lysosomal content due to the deficiency of CPA and CPB enzymes $[42,60]$. This inability to complete transformation leads to a reduced survival rates inside macrophages in vitro $[33,35,42,60]$ and in vivo [35].

The inhibition of Hsp90 in cancer cells results in an increase in the accumulation of ubiquitylated proteins in the cytosol [19], and subsequently, proteasome overload, leading to both the accumulation of unfolded and misfolded proteins $[23,61]$ and protein aggregate formation [62-64]. We speculate that a similar event could take place in parasites treated with 17-AAG. The accumulation of polyubiquitylated proteins following treatment with Hsp90 inhibitors in animal models of neurodegenerative disease $[17,24,65]$ inhibited protein aggregate formation from the activation of Hsp70 and Hsp40 [48,66]. The present study showed that treating Leishmania parasites with 17-AAG led to the accumulation of ubiquitylated proteins at levels similar to those observed in parasites treated with the proteasome inhibitor, MG132. Although 17-AAG treatment induced the accumulation of polyubiquitylated proteins, Hsp90 inhibition most likely did not result in proteasome overload, as no enhancement in the formation of protein aggregates was detected (Figure 6), likely due to the activation of other Hsps [66].

In sum, our findings evidence that Leishmania cell death caused by 17-AAG is associated with abnormal activation of the autophagic pathway, resulting in the formation of autophagosomes unable to achieve complete autophagolysosomal maturation and therefore incapable of degrading engulfed material.

Author Contributions: A.L.d.O.A.P., J.C.M. and P.S.T.V. conceived and designed the experiments; A.L.d.O.A.P., B.C., B.R.S.D., L.C.P., Y.d.S.L. and J.P.B.d.M. performed the experiments; A.L.d.O.A.P., B.C., B.R.S.D., L.C.P., J.P.B.d.M., J.C.M. and P.S.T.V. analyzed the data; P.S.T.V. and J.C.M. contributed reagents/materials/analysis tools; A.L.d.O.A.P. and P.S.T.V. wrote the manuscript. All authors contributed to manuscript elaboration and revision and approved the final version prior to submission. All authors have read and agreed to the published version of the manuscript.

Funding: This research was funded by Coordenação de Aperfeiçoamento de Pessoal de Nível Superior-Brasil (CAPES)—Finance Code 001. This work was also supported by grants from Fundação de Amparo à Pesquisa do Estado da Bahia (P.S.T.V. http:/ / www.fapesb.ba.gov.br, (accessed on 30 August 2013) and CNPq (P.S.T.V.-Universal 422867/2016-0 http:/ / www.cnpq.br, (accessed on 30 August 2016) and the Medical Research Council (MR/K019384/1). P.S.T.V. holds a grant from CNPq for productivity in research (307832/2015-5). B.C. was supported by a Medical Research Council studentship.

Institutional Review Board Statement: Not applicable.

Informed Consent Statement: Not applicable.

Data Availability Statement: Not applicable.

Acknowledgments: The authors would like to thank Andris K. Walter for English language revision and manuscript copyediting assistance. 
Conflicts of Interest: The authors declare no conflict of interest. The funders had no role in the design of the study; in the collection, analyses, or interpretation of data; in the writing of the manuscript, or in the decision to publish the results.

\section{References}

1. Herwaldt, B.L. Leishmaniasis. Lancet 1999, 354, 1191-1199. [CrossRef]

2. Banuls, A.L.; Hide, M.; Prugnolle, F. Leishmania and the leishmaniases: A parasite genetic update and advances in taxonomy, epidemiology and pathogenicity in humans. Adv. Parasitol. 2007, 64, 1-109. [CrossRef] [PubMed]

3. World Health Organization. Control of the Leishmaniases. World Health Organ. Tech. Rep. Ser. 2010, Xii-Xiii, 1-186.

4. Oliveira, L.F.; Schubach, A.O.; Martins, M.M.; Passos, S.L.; Oliveira, R.V.; Marzochi, M.C.; Andrade, C.A. Systematic review of the adverse effects of cutaneous leishmaniasis treatment in the new world. Acta Trop. 2011, 118, 87-96. [CrossRef] [PubMed]

5. Croft, S.L.; Seifert, K.; Yardley, V. Current scenario of drug development for leishmaniasis. Indian J. Med. Res. 2006, 123, 399-410. [PubMed]

6. Croft, S.L.; Sundar, S.; Fairlamb, A.H. Drug resistance in leishmaniasis. Clin. Microbiol. Rev. 2006, 19, 111-126. [CrossRef] [PubMed]

7. De Menezes, J.P.; Guedes, C.E.; Petersen, A.L.; Fraga, D.B.; Veras, P.S. Advances in development of new treatment for leishmaniasis. BioMed Res. Int. 2015, 2015, 815023. [CrossRef]

8. Angel, S.O.; Matrajt, M.; Echeverria, P.C. A review of recent patents on the protozoan parasite hsp90 as a drug target. Recent Pat. Biotechnol. 2013, 7, 2-8. [CrossRef]

9. Roy, N.; Nageshan, R.K.; Ranade, S.; Tatu, U. Heat shock protein 90 from neglected protozoan parasites. Biochim. Biophys. Acta 2012, 1823, 707-711. [CrossRef]

10. Shonhai, A.; Maier, A.G.; Przyborski, J.M.; Blatch, G.L. Intracellular protozoan parasites of humans: The role of molecular chaperones in development and pathogenesis. Protein Pept. Lett. 2011, 18, 143-157. [CrossRef]

11. Wiesgigl, M.; Clos, J. Heat shock protein 90 homeostasis controls stage differentiation in leishmania donovani. Mol. Biol. Cell 2001, 12, 3307-3316. [CrossRef]

12. Ahn, H.J.; Kim, S.; Nam, H.W. Molecular cloning of the 82-kda heat shock protein (hsp90) of toxoplasma gondii associated with the entry into and growth in host cells. Biochem. Biophys. Res. Commun. 2003, 311, 654-659. [CrossRef]

13. Pallavi, R.; Roy, N.; Nageshan, R.K.; Talukdar, P.; Pavithra, S.R.; Reddy, R.; Venketesh, S.; Kumar, R.; Gupta, A.K.; Singh, R.K.; et al. Heat shock protein 90 as a drug target against protozoan infections: Biochemical characterization of hsp90 from plasmodium falciparum and trypanosoma evansi and evaluation of its inhibitor as a candidate drug. J. Biol. Chem. 2010, 285, 37964-37975. [CrossRef]

14. Meyer, K.J.; Shapiro, T.A. Potent antitrypanosomal activities of heat shock protein 90 inhibitors in vitro and in vivo. J. Infect. Dis. 2013, 208, 489-499. [CrossRef]

15. Petersen, A.L.; Guedes, C.E.; Versoza, C.L.; Lima, J.G.; de Freitas, L.A.; Borges, V.M.; Veras, P.S. 17-aag kills intracellular leishmania amazonensis while reducing inflammatory responses in infected macrophages. PLoS ONE 2012, 7, e49496. [CrossRef]

16. Santos, D.M.; Petersen, A.L.; Celes, F.S.; Borges, V.M.; Veras, P.S.; de Oliveira, C.I. Chemotherapeutic potential of 17-aag against cutaneous leishmaniasis caused by leishmania (viannia) braziliensis. PLoS Negl. Trop. Dis. 2014, 8, e3275. [CrossRef]

17. Tokui, K.; Adachi, H.; Waza, M.; Katsuno, M.; Minamiyama, M.; Doi, H.; Tanaka, K.; Hamazaki, J.; Murata, S.; Tanaka, F.; et al. 17-dmag ameliorates polyglutamine-mediated motor neuron degeneration through well-preserved proteasome function in an sbma model mouse. Hum. Mol. Genet. 2009, 18, 898-910. [CrossRef]

18. Neckers, L.; Workman, P. Hsp90 molecular chaperone inhibitors: Are we there yet? Clin. Cancer Res. 2012, 18, 64-76. [CrossRef]

19. Isaacs, J.S.; Xu, W.; Neckers, L. Heat shock protein 90 as a molecular target for cancer therapeutics. Cancer Cell 2003, 3, $213-217$. [CrossRef]

20. Zuehlke, A.; Johnson, J.L. Hsp90 and co-chaperones twist the functions of diverse client proteins. Biopolymers 2010, 93, 211-217. [CrossRef]

21. Driscoll, J.J.; Chowdhury, R.D. Molecular crosstalk between the proteasome, aggresomes and autophagy: Translational potential and clinical implications. Cancer Lett. 2012, 325, 147-154. [CrossRef]

22. Wolff, S.; Weissman, J.S.; Dillin, A. Differential scales of protein quality control. Cell 2014, 157, 52-64. [CrossRef]

23. Tyedmers, J.; Mogk, A.; Bukau, B. Cellular strategies for controlling protein aggregation. Nat. Rev. Mol. Cell Biol. 2010, 11, 777-788. [CrossRef]

24. Sittler, A.; Lurz, R.; Lueder, G.; Priller, J.; Lehrach, H.; Hayer-Hartl, M.K.; Hartl, F.U.; Wanker, E.E. Geldanamycin activates a heat shock response and inhibits huntingtin aggregation in a cell culture model of huntington's disease. Hum. Mol. Genet. 2001, 10, 1307-1315. [CrossRef]

25. Mizushima, N.; Komatsu, M. Autophagy: Renovation of cells and tissues. Cell 2011, 147, 728-741. [CrossRef] [PubMed]

26. Cheng, Y.; Ren, X.; Hait, W.N.; Yang, J.M. Therapeutic targeting of autophagy in disease: Biology and pharmacology. Pharmacol. Rev. 2013, 65, 1162-1197. [CrossRef] [PubMed]

27. Klionsky, D.J.; Emr, S.D. Autophagy as a regulated pathway of cellular degradation. Science 2000, 290, 1717-1721. [CrossRef] [PubMed] 
28. Yorimitsu, T.; Klionsky, D.J. Eating the endoplasmic reticulum: Quality control by autophagy. Trends Cell Biol. 2007, 17, $279-285$. [CrossRef] [PubMed]

29. Mizushima, N.; Klionsky, D.J. Protein turnover via autophagy: Implications for metabolism. Annu. Rev. Nutr. 2007, 27, 19-40. [CrossRef]

30. Klionsky, D.J.; Abdalla, F.C.; Abeliovich, H.; Abraham, R.T.; Acevedo-Arozena, A.; Adeli, K.; Agholme, L.; Agnello, M.; Agostinis, P.; Aguirre-Ghiso, J.A.; et al. Guidelines for the use and interpretation of assays for monitoring autophagy. Autophagy 2012, 8, 445-544. [CrossRef]

31. Duszenko, M.; Ginger, M.L.; Brennand, A.; Gualdron-Lopez, M.; Colombo, M.I.; Coombs, G.H.; Coppens, I.; Jayabalasingham, B.; Langsley, G.; de Castro, S.L.; et al. Autophagy in protists. Autophagy 2011, 7, 127-158. [CrossRef]

32. Meijer, W.H.; van der Klei, I.J.; Veenhuis, M.; Kiel, J.A. Atg genes involved in non-selective autophagy are conserved from yeast to man, but the selective cvt and pexophagy pathways also require organism-specific genes. Autophagy 2007, 3, 106-116. [CrossRef]

33. Besteiro, S.; Williams, R.A.; Morrison, L.S.; Coombs, G.H.; Mottram, J.C. Endosome sorting and autophagy are essential for differentiation and virulence of leishmania major. J. Biol. Chem. 2006, 281, 11384-11396. [CrossRef]

34. Besteiro, S.; Williams, R.A.; Coombs, G.H.; Mottram, J.C. Protein turnover and differentiation in leishmania. Int. J. Parasitol. 2007, 37, 1063-1075. [CrossRef]

35. Williams, R.A.; Smith, T.K.; Cull, B.; Mottram, J.C.; Coombs, G.H. Atg5 is essential for atg8-dependent autophagy and mitochondrial homeostasis in leishmania major. PLoS Pathog 2012, 8, e1002695. [CrossRef]

36. Meijer, A.J.; Codogno, P. Regulation and role of autophagy in mammalian cells. Int. J. Biochem. Cell Biol. 2004, 36, 2445-2462. [CrossRef]

37. Levine, B.; Klionsky, D.J. Development by self-digestion: Molecular mechanisms and biological functions of autophagy. Dev. Cell 2004, 6, 463-477. [CrossRef]

38. Levine, B.; Yuan, J. Autophagy in cell death: An innocent convict? J. Clin. Investig. 2005, 115, 2679-2688. [CrossRef]

39. Sengupta, S.; Chowdhury, S.; Bosedasgupta, S.; Wright, C.W.; Majumder, H.K. Cryptolepine-induced cell death of leishmania donovani promastigotes is augmented by inhibition of autophagy. Mol. Biol. Int. 2011, 2011, 187850. [CrossRef]

40. Cull, B.; Prado Godinho, J.L.; Fernandes Rodrigues, J.C.; Frank, B.; Schurigt, U.; Williams, R.A.; Coombs, G.H.; Mottram, J.C. Glycosome turnover in leishmania major is mediated by autophagy. Autophagy 2014, 10, 2143-2157. [CrossRef]

41. Huete-Perez, J.A.; Engel, J.C.; Brinen, L.S.; Mottram, J.C.; McKerrow, J.H. Protease trafficking in two primitive eukaryotes is mediated by a prodomain protein motif. J. Biol. Chem. 1999, 274, 16249-16256. [CrossRef]

42. Williams, R.A.; Woods, K.L.; Juliano, L.; Mottram, J.C.; Coombs, G.H. Characterization of unusual families of atg8-like proteins and atg12 in the protozoan parasite leishmania major. Autophagy 2009, 5, 159-172. [CrossRef]

43. Bolte, S.; Cordelieres, F.P. A guided tour into subcellular colocalization analysis in light microscopy. J. Microsc. 2006, 224, 213-232. [CrossRef]

44. Jang, H.H.; Lee, K.O.; Chi, Y.H.; Jung, B.G.; Park, S.K.; Park, J.H.; Lee, J.R.; Lee, S.S.; Moon, J.C.; Yun, J.W.; et al. Two enzymes in one; two yeast peroxiredoxins display oxidative stress-dependent switching from a peroxidase to a molecular chaperone function. Cell 2004, 117, 625-635. [CrossRef]

45. Amaravadi, R.K.; Thompson, C.B. The roles of therapy-induced autophagy and necrosis in cancer treatment. Clin. Cancer Res. 2007, 13, 7271-7279. [CrossRef]

46. Cervantes, S.; Bunnik, E.M.; Saraf, A.; Conner, C.M.; Escalante, A.; Sardiu, M.E.; Ponts, N.; Prudhomme, J.; Florens, L.; Le Roch, K.G. The multifunctional autophagy pathway in the human malaria parasite, plasmodium falciparum. Autophagy 2014, 10, 80-92. [CrossRef]

47. Hoppe, H.C.; van Schalkwyk, D.A.; Wiehart, U.I.; Meredith, S.A.; Egan, J.; Weber, B.W. Antimalarial quinolines and artemisinin inhibit endocytosis in plasmodium falciparum. Antimicrob. Agents Chemother. 2004, 48, 2370-2378. [CrossRef]

48. Akerfelt, M.; Morimoto, R.I.; Sistonen, L. Heat shock factors: Integrators of cell stress, development and lifespan. Nat. Rev. Mol. Cell Biol. 2010, 11, 545-555. [CrossRef]

49. Hartl, F.U. Molecular chaperones in cellular protein folding. Nature 1996, 381, 571-579. [CrossRef]

50. Hartl, F.U.; Bracher, A.; Hayer-Hartl, M. Molecular chaperones in protein folding and proteostasis. Nature 2011, 475, 324-332. [CrossRef]

51. Chen, C.Y.; Balch, W.E. The hsp90 chaperone complex regulates gdi-dependent rab recycling. Mol. Biol. Cell 2006, 17, 3494-3507. [CrossRef] [PubMed]

52. Lotz, G.P.; Brychzy, A.; Heinz, S.; Obermann, W.M. A novel hsp90 chaperone complex regulates intracellular vesicle transport. J. Cell Sci. 2008, 121, 717-723. [CrossRef] [PubMed]

53. Di Cristina, M.; Dou, Z.; Lunghi, M.; Kannan, G.; Huynh, M.H.; McGovern, O.L.; Schultz, T.L.; Schultz, A.J.; Miller, A.J.; Hayes, B.M.; et al. Toxoplasma depends on lysosomal consumption of autophagosomes for persistent infection. Nat. Microbiol. 2017, 2, 17096. [CrossRef] [PubMed]

54. Choi, A.M.; Ryter, S.W.; Levine, B. Autophagy in human health and disease. N. Engl. J. Med. 2013, 368, 651-662. [CrossRef]

55. Degenhardt, K.; Mathew, R.; Beaudoin, B.; Bray, K.; Anderson, D.; Chen, G.; Mukherjee, C.; Shi, Y.; Gelinas, C.; Fan, Y.; et al. Autophagy promotes tumor cell survival and restricts necrosis, inflammation, and tumorigenesis. Cancer Cell 2006, $10,51-64$. [CrossRef] 
56. Lum, J.J.; Bauer, D.E.; Kong, M.; Harris, M.H.; Li, C.; Lindsten, T.; Thompson, C.B. Growth factor regulation of autophagy and cell survival in the absence of apoptosis. Cell 2005, 120, 237-248. [CrossRef]

57. Nguyen, H.M.; Berry, L.; Sullivan, W.J., Jr.; Besteiro, S. Autophagy participates in the unfolded protein response in toxoplasma gondii. FEMS Microbiol. Lett. 2017, 364. [CrossRef]

58. Mizushima, N.; Levine, B.; Cuervo, A.M.; Klionsky, D.J. Autophagy fights disease through cellular self-digestion. Nature 2008, 451, 1069-1075. [CrossRef]

59. Chung, Y.; Lee, J.; Jung, S.; Lee, Y.; Cho, J.W.; Oh, Y.J. Dysregulated autophagy contributes to caspase-dependent neuronal apoptosis. Cell Death Dis. 2018, 9, 1189. [CrossRef]

60. Williams, R.A.; Tetley, L.; Mottram, J.C.; Coombs, G.H. Cysteine peptidases cpa and cpb are vital for autophagy and differentiation in leishmania mexicana. Mol. Microbiol. 2006, 61, 655-674. [CrossRef]

61. Theodoraki, M.A.; Caplan, A.J. Quality control and fate determination of hsp90 client proteins. Biochim. Biophys. Acta 2012, 1823, 683-688. [CrossRef]

62. Janen, S.B.; Chaachouay, H.; Richter-Landsberg, C. Autophagy is activated by proteasomal inhibition and involved in aggresome clearance in cultured astrocytes. Glia 2010, 58, 1766-1774. [CrossRef]

63. Grumati, P.; Dikic, I. Ubiquitin signaling and autophagy. J. Biol. Chem. 2018, 293, 5404-5413. [CrossRef]

64. Grumati, P.; Morozzi, G.; Holper, S.; Mari, M.; Harwardt, M.I.; Yan, R.; Muller, S.; Reggiori, F.; Heilemann, M.; Dikic, I. Full length rtn3 regulates turnover of tubular endoplasmic reticulum via selective autophagy. Elife 2017, 6. [CrossRef]

65. Silva-Fernandes, A.; Duarte-Silva, S.; Neves-Carvalho, A.; Amorim, M.; Soares-Cunha, C.; Oliveira, P.; Thirstrup, K.; TeixeiraCastro, A.; Maciel, P. Chronic treatment with 17-dmag improves balance and coordination in a new mouse model of machadojoseph disease. Neurotherapeutics 2014, 11, 433-449. [CrossRef]

66. Bose, S.; Cho, J. Targeting chaperones, heat shock factor-1, and unfolded protein response: Promising therapeutic approaches for neurodegenerative disorders. Ageing Res. Rev. 2017, 35, 155-175. [CrossRef] 